\title{
ARTICLE
}

\section{Information technology and Indian Agriculture}

\author{
ANUPSINGH THAKUR AND JYOSTANA KSHIRSAGAR
}

The role of information technology to develop agricultural research, education and extension results in improve quality of life in rural area is well established. IT can help an average Indian farmer to get relevant information regarding agro-inputs, crop production technologies, agro processing, market support, agro-finance and management of farm agri-business. Technologically it is possible to develop suitable systems to cater to the information needs of Indian farmer. User friendly systems, particularly with content in local languages, can generate interest in the farmers and others working at the grassroots. It is possible to create dedicated networks or harness the power of internet to make these services are available to all parts of the country.

\section{IT in agricultural management :}

In India, the gap between the information rich and information poor is getting wider. New IT world is creating ways to solve problems of rural poverty, inequality and giving an opportunity to link the gap between information-rich and information-poor and support sustainable development in rural and agricultural communities. This is a giant challenge to reach remote rural community, however, remote rural communities still lack basic communication infrastructure. The challenge is not only to improve the accessibility of communication technology to the rural population but also to improve the relevance of information to local development.

\section{IT for agricultural teachers and educational planners:}

In order to see successful integration of IT in agricultural education we need to empower teachers of agricultural schools, colleges and universities and so also administrators and educational planners. For this purpose at the elementary stage, we are required to arrange training of these personnel in fundamentals of computers and then gradually introduce the advanced modules for computer applications.

\section{New IT dimensions of agricultural education in India :}

To prepare the agricultural graduates capable to meet the challenges of the new millennium, they should be given course on International Agriculture, WTO, trade related intellectual property rights (TRIPs), global conventions on climate, biodiversity and desertification, computer technology, patent and trade literacy, international standards. For this IT can play important role. So introduction to computers, application of software, data base management systems, power point, drawing software, computer programming, multimedia, Internet should be a part of their course curriculum.

\section{IT in agricultural extension management :}

\section{E-extension:}

This a new term coined for electronic extension approach, which is otherwise can be called as IT oriented 